\title{
Molecular identification of Acetobacter pasteurianus and Lactobacillus fermentum, contaminating an ethanol industry in the state of Pernambuco
}

\author{
Mariana Sampaio*, Glícia Calazans, Márcia Silva \\ From 5th Congress of the Brazilian Biotechnology Society (SBBIOTEC) \\ Florianópolis, Brazil. 10-14 November 2013
}

\begin{abstract}
Introduction
Acetobacter pasteurianus is among the major bacteria responsible for acetic fermentation and gives the characteristic taste of vinegar, can be found as a contaminant of wine production industry. In industrial fermentation is frequent contamination by lactic acid bacteria such as Lactobacillus fermentum that competes with the yeast for nutrients and inhibiting their growth, slow the fermentation and impair the production of ethanol [1]. (AIM) The objective of this study is the molecular identification of bacteria isolated as contaminants of an ethanol industry in the state of Pernambuco, by sequencing the $16 \mathrm{~S}$ ribosomal gene (16S rDNA).
\end{abstract}

\section{Methods}

The samples were cultured in a sucrose syrup at $35^{\circ} \mathrm{C}$ for 24 hours and subjected to DNA isolation using the protocol of Sambrook et al (1989) [2] by extraction with phenol/chloroform and precipitation with isopropanol. The PCR reaction was performed using $16 \mathrm{~S}$ rDNA primers then analyzed by agarose gel electrophoresis observed in UV transilluminator and revealed. The amplified product of the $16 \mathrm{~S}$ rDNA gene was purified, sequenced and the data were aligned with the tool BLASTn (Basic Lenth Alignamment Search Tool) algorithm enabling the identification by comparison to other sequences deposited in the GenBank database from NCBI (National Center for Biotechnology Information).

\section{Results and conclusions}

The PCR products of the gene $16 \mathrm{~S}$ rDNA of the bacteria had a molecular weight of approximately 1500 base pairs [3]. Thus, the samples showed to be able to step sequencing and soon after had their sequences compared in the database and showed high similarity (99\%) with Acetobacter pasteurianus and Lactobacillus fermentum . One of the bacteria showed up as producer of biopolymer, L. fermentum, this drew attention by quantity and rheological properties of a polymer produced molasses medium. The molecular technique used revealed a high degree of conservation of the $16 \mathrm{~S}$ rDNA gene and comparison of the sequence obtained in this study with sequences deposited in GenBank database resulted in strains of known species showing similarity with the sequences under study.

Acknowledgements

The Fundação de Amparo a Ciência e Tecnologia de Pernambuco (FACEPE) for financial Support.

Published: 1 October 2014

\section{References}

1. Thomas KC, Hynes SH, Ingledew WM: Influence of Medium Buffering Capacity on Inhibition of Saccharomyces cerevisiae Growth by Acetic and Lactic Acids. Applied and environmental microbiology, 2002, 68:1616-1623.

2. Sambrook J, Fritsch EF, Maniatis T: Molecular cloning: a laboratory manual. Cold Spring Harbor Laboratory Press 1989, 3:253.

3. Woese CR: Interpreting the universal phylogenetic tree. Proceedings of the National Academy of Sciences 2000, 97:8392-8396.

doi:10.1186/1753-6561-8-S4-P200

Cite this article as: Sampaio et al:: Molecular identification of Acetobacter pasteurianus and Lactobacillus fermentum, contaminating an ethanol industry in the state of Pernambuco. BMC Proceedings 2014 8(Suppl 4):P200.

Universidade Federal de Pernambuco, Recife, PE, Brasil 